\title{
The Relationship between Coping with Stress and Employment in Patients Receiving Maintenance Hemodialysis
}

\author{
Jiro TAKAKI and Eiji YANO \\ Department of Hygiene \& Public Health, Teikyo University School of Medicine, Japan
}

\begin{abstract}
The Relationship Between Coping with Stress and Employment in Patients Receiving Maintenance Hemodialysis: Jiro TAKAKI, et al. Department of Hygiene \& Public Health, Teikyo University School of Medicine-The goal of this study was to assess the relationship between emotion- and task-oriented coping (EOC/TOC) with stress and employment in patients undergoing maintenance hemodialysis. Individuals aged 18 to $64 \mathrm{yr}$ who had uremia and had been undergoing hemodialysis regularly for at least three months were evaluated according to sociodemographic and clinical factors. Work status was defined using the most recent International Labour Organization definitions. Patients were requested to complete the following questionnaires: the Japanese version of the Coping Inventory for Stressful Situations, the Short Form-36 Health Survey, an item on itchiness, the Self-Efficacy on Health-Related Behavior Scale, the Japanese version of the Health Locus of Control Scale, the Social Support Scale, and the Japanese version of the Hospital Anxiety and Depression Scale. A total of 317 individuals participated in this study. Among men, age, physical functioning, EOC, and depression differed significantly $(p<0.05)$ depending on employment. Among women, marital status, household composition, EOC, depression, and anxiety differed significantly $(p<0.05)$ depending on employment. TOC was not significantly associated with employment in either sex. Multiple logistic regression analyses, including possible confounders, indicated that when EOC increased by 10 points, the associated adjusted odds ratio of an unemployed or economically inactive status changed by $1.48(95 \%$ confidence interval, $1.04-2.11 ; p=0.030)$ in men and by 1.88 (95\% confidence interval, 1.02$3.46 ; p=0.042)$ in women. These results suggest that EOC is associated with employment in patients
\end{abstract}

Received May 25, 2005; Accepted Mar 20, 2006

Correspondence to: J. TAKAKI, Department of Hygiene and Public Health, Teikyo University School of Medicine, 2-11-1 Kaga, Itabashi-ku, Tokyo 173-8605, Japan

(e-mail: jirosinryounaika-tky@umin.ac.jp) receiving maintenance hemodialysis. (J Occup Health 2006; 48: 276-283)

Key words: Hemodialysis, Coping, Stress, Emotion, Employment, Function

Emotion-oriented coping (EOC) is a way of confronting and dealing with stressful situations in which emotional responses are directed inwardly (e.g., an individual blames him/herself for being too emotional, gets angry or upset, cries, becomes tense, or daydreams $)^{1)}$. EOC does not change the objective terms of a personenvironment relationship but only how these terms are interpreted $^{1)}$. EOC may temporarily reduce emotional distress but offers few adaptive outcomes ${ }^{2}$. Studies have found that EOC was associated with poor perceived performance among graduate business school students ${ }^{3)}$, poor employee adjustment among middle managers of a public sector organization ${ }^{4}$, poor job-related well-being among teleworkers ${ }^{5)}$, psychological distress among police officers $^{6}$, burnout among public school teachers ${ }^{7}$ and extension agents ${ }^{8}$, exhaustion and perceived stress among general practitioners ${ }^{9)}$, job stress among employees of a computer-information systems company ${ }^{10)}$, job strain among nurses ${ }^{11)}$ and working women ${ }^{12)}$, and poor sales presentation effectiveness and pessimism among salespeople ${ }^{13-15)}$.

Conversely, task-oriented coping (TOC) is a means of confronting and dealing with stressful situations using purposeful task-oriented efforts aimed at problem solving, cognitively restructuring the problem, or attempting to alter the situation ${ }^{1)}$. Some occupational stress studies have demonstrated that task-oriented problem-solving coping strategies are the most adaptive way of dealing with pressures associated with workload, inadequate resources, role ambiguity, and other sources of stress $2,8,13-16$ ). However, other studies have not associated TOC with an

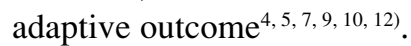

As a result of the Government Action Plan for Persons With Disabilities enacted in 2003, Japan actively promotes social participation and economic independence 
among persons with disabilities ${ }^{17}$. In December 2003, there were 237,710 patients with uremia receiving dialysis in Japan, which has the world's highest rate of dialysis treatment $(1,862.7 \text { per million people })^{18)}$. Although most treatment costs are covered by national medical insurance ${ }^{19}$ ), it would benefit patients receiving dialysis, as well as society as a whole, if they were to achieve economic independence.

Persons with disabilities often encounter stressful situations in their work environments. Based on the aforementioned studies on EOC and TOC, we hypothesized that, among patients undergoing maintenance hemodialysis (HD), EOC would be negatively associated with employment, whereas TOC would be positively associated with employment. To test this hypothesis, we assessed the relationship of EOC and TOC with employment in the study population. Previous studies found that factors such as dialysis duration, educational level, physical functioning ability, and comorbidities were associated with the work status of patients undergoing dialysis ${ }^{20-24)}$. The present study examined these factors and other possible confounders.

\section{Subjects and Methods}

The inclusion criteria for the study selected patients with uremia who had received HD regularly for at least three months (criterion A), had no serious intellectual impairment and were able to complete the questionnaires (criterion B), and were 18 to $64 \mathrm{yr}$ old (criterion C). Eligible patients were evaluated at four medical facilities in Japan: the Yuuai Clinic in Saitama, the Bousei Tanashi Clinic, Tokyo Kensei Hospital, and the Nishi Clinic in Tokyo. We conducted the study according to the universal ethical guidelines established by the Declaration of Helsinki. Approval from the institutional review board of Teikyo University was obtained for the study, and all patients who enrolled provided their informed written consent.

Participants answered questions about their age, sex, duration of HD, marital status, household composition, educational achievement (years of formal schooling), and current work status. Work status was defined using the most recent International Labour Organization (ILO) definitions, which were adopted in October 1982 at the 13th International Conference of Labour Statisticians held in Geneva. According to the ILO definitions, 'employment' includes paid employment, selfemployment, and unpaid family employees at work. Students, homemakers, and others who engaged mainly in non-economic activities but who were also paid employees or self-employed were classified as being employed. Unemployed persons had to be available for work and had to be actively seeking a job. Participants who did not fit any of these categories were considered economically inactive. Some women receiving HD felt discouraged and believed that no jobs were available to them even if they wanted to work, which made it difficult to discriminate between unemployed and economically inactive women. Therefore, we compared patients who were employed with those who were either unemployed or economically inactive.

EOC and TOC were evaluated using the Coping Inventory for Stressful Situations (CISS). This is a selfreport questionnaire, that reliably and validly assesses preferred characteristics or typical manners of coping with stress, in which higher scores indicate greater coping activity ${ }^{1)}$. The score for each subscale can range from 16 to $80^{1}$. The Japanese version of the CISS also has high construct validity and reliability ${ }^{25}$.

We also assessed possible confounders. Current physical performance or activity status was evaluated using the Short Form-36 (SF-36) Health Survey subscale of physical functioning. The SF-36 is a self-report questionnaire that assesses health-related quality of life ${ }^{26)}$. A higher score indicates better physical functioning. The Japanese version of the SF-36 has high construct validity and reliability ${ }^{27)}$.

Itchiness was used as a disease-related stressors. The item was "How was your itchiness last month? Much or a little $=1$. Little or none $=0 .{ }^{28}$ )

Self-efficacy is defined as the belief that one is capable of executing a given course of action ${ }^{29)}$ and was evaluated using the Self-Efficacy on Health-Related Behavior Scale, which has high reliability ${ }^{30)}$. A higher score indicates greater self-efficacy ${ }^{30}$.

The internal health locus of control was evaluated using the Japanese version of the Health Locus of Control Scale, which was developed by Horige based on Wallston's Multidimensional Health Locus of Control Scale, and has high reliability ${ }^{31,32)}$.

Social support was evaluated using the Social Support Scale, which was developed as a means of assessing the social support that influences motivation for long-term treatment among patients with chronic disease. It has high construct validity and reliability ${ }^{33)}$. A higher score indicates better social support ${ }^{33)}$.

Depression and anxiety were scored using the Japanese version of the Hospital Anxiety and Depression Scale (HADS), which has high construct validity and reliability ${ }^{34-37)}$. The higher the score, the worse the status $^{34)}$.

After all questionnaires were completed, the subjects'medical records were reviewed to obtain data about the dialysis dose $(\mathrm{Kt} / \mathrm{V})^{38)}$, cause of renal failure, and comorbidities.

Differences in the polychotomous categorical variable (work status) were compared between the sexes using the chi-squared test. In previous studies in Japan, factors associated with work status have differed greatly depending on sex, so we assessed each sex separately. 
Differences in continuous variables that met assumptions of normality were compared between employed patients versus those considered otherwise, using Student's or Welch's $t$-test. Continuous variables that did not meet assumptions of normality and ordinal variables were compared using the Mann-Whitney $U$ test. Dichotomous variables were compared using Fisher's exact test.

Multiple logistic regression analyses were performed using a forward, stepwise method with the likelihood ratio statistics including EOC, TOC, marital status, living alone or with someone, educational level, cause of renal failure, comorbidities, a disease-related stressor, age, duration of $\mathrm{HD}, \mathrm{Kt} / \mathrm{V}$, physical functioning, depression, anxiety, internal health locus of control, self-efficacy, and social support as variables in order to assess independent associations with employment. Both entry and exit criteria were set at $p=0.15$. Multivariate analyses used list-wise deletion. All $p$-values were two-tailed, and the significance level was set at $p<0.05$. All statistical analyses were performed using SPSS (Version 10.0J, Tokyo, Japan).

\section{Results}

Initially, 481 patients receiving $\mathrm{HD}$ agreed to participate in the study. During the recruitment process, criterion A excluded four patients, and criterion $\mathrm{C}$ excluded 160 patients, resulting in a total of 164 patients being excluded from the study. The remaining 317 patients, all Asian and residents of Japan, were subsequently enrolled in the study. Table 1 shows their work status by sex; work status differed significantly $(p<0.001)$ between the two sexes. Tables 2 and 3 show the demographic, clinical, and psychological characteristics of both sexes and the significance of their differences by employment, respectively. Among men, age, physical functioning, EOC, and depression differed significantly $(p<0.05)$ depending on employment. Among women, marital status, household composition, EOC, depression, and anxiety differed significantly $(p<0.05)$ depending on employment. TOC was not significantly associated with employment in either sex.

Table 4 shows the results of the multiple logistic regression analyses in men. EOC was significantly associated with an unemployed or economically inactive status; when EOC increased by 10 points, the associated adjusted odds ratio of an unemployed or economically inactive status changed by 1.48 (95\% confidence interval [CI], 1.04-2.11; Wald statistic, $4.7 ; p=0.030)$. Table 5 shows the results of the multiple logistic regression analyses in women. EOC was also significantly associated with an unemployed or economically inactive status in women; when EOC increased by 10 points, the associated adjusted odds ratio of an unemployed or economically inactive status changed by 1.88 (95\% CI, 1.02-3.46; Wald statistic, $4.1 ; p=0.042)$. TOC was not significantly associated with unemployed or economically inactive status in either sex.

\section{Discussion}

In patients receiving maintenance $\mathrm{HD}$, EOC was negatively associated with employment among both men and women. The association was significant for each sex according to both univariate and multivariate analyses. Conversely, TOC was not significantly associated with employment. To our knowledge, no previous reports have described the relationship between employment and coping mechanisms in persons with physical disabilities.

Previous studies have reported that being female was associated with EOC $^{39-43}$, so sex may be a confounder in the association between EOC and employment. However, we found a significant association between EOC and employment in analyses of each sex.

Among the factors previously shown to be associated with the work status of dialysis patients (i.e., duration of dialysis, educational level, physical functioning, and

Table 1. Participants' work status by sex

\begin{tabular}{|c|c|c|c|c|}
\hline & \multicolumn{2}{|c|}{ Male } & \multicolumn{2}{|c|}{ Female } \\
\hline & $\mathrm{N}$ & $\%$ & $\mathrm{~N}$ & $\%$ \\
\hline \multicolumn{5}{|l|}{ Employed patient } \\
\hline Own-account worker & 40 & 19.1 & 10 & 9.3 \\
\hline \multicolumn{5}{|l|}{ Employee } \\
\hline Full-time & 108 & 51.7 & 12 & 11.1 \\
\hline Part-time & 5 & 2.4 & 9 & 8.3 \\
\hline \multicolumn{5}{|c|}{ Unemployed or economically inactive patient } \\
\hline Homemaker & 0 & 0.0 & 61 & 56.5 \\
\hline Student & 1 & 0.5 & 0 & 0.0 \\
\hline Others & 55 & 26.3 & 16 & 14.8 \\
\hline Total & 209 & 100.0 & 108 & 100.0 \\
\hline
\end{tabular}


Table 2. Male patients' demographic, clinical and psychological characteristics and significances of their differences by employment

\begin{tabular}{|c|c|c|c|c|c|c|c|c|}
\hline & & \multicolumn{3}{|c|}{ Employed patients } & \multicolumn{3}{|c|}{$\begin{array}{l}\text { Unemployed or economically } \\
\text { inactive patients }\end{array}$} & \multirow[t]{2}{*}{$p$-value } \\
\hline & & $\mathrm{N}$ & $\%$ & Total $\mathrm{n}$ & $\mathrm{N}$ & $\%$ & Total $n$ & \\
\hline \multicolumn{2}{|l|}{ Married } & 116 & 75.8 & 153 & 34 & 64.2 & 53 & 0.109 \\
\hline \multicolumn{2}{|c|}{ Living with someone } & 132 & 86.3 & 153 & 43 & 78.2 & 55 & 0.196 \\
\hline \multirow[t]{3}{*}{ Education } & Less than $12 \mathrm{yr}$ & 23 & 15.0 & 153 & 10 & 17.9 & 56 & 0.184 \\
\hline & $12 \mathrm{yr}$ & 61 & 39.9 & & 27 & 48.2 & & \\
\hline & More than $12 \mathrm{yr}$ & 69 & 45.1 & & 19 & 33.9 & & \\
\hline \multicolumn{2}{|c|}{ Diabetes mellitus as the cause of renal failure } & 29 & 19.0 & 153 & 13 & 23.2 & 56 & 0.559 \\
\hline \multicolumn{2}{|c|}{ Patients with cardiovascular disease } & 7 & 4.6 & 153 & 6 & 10.7 & 56 & 0.115 \\
\hline \multicolumn{2}{|c|}{ Patients with gastrointestinal disease } & 32 & 20.9 & 153 & 19 & 33.9 & 56 & 0.068 \\
\hline \multirow{2}{*}{\multicolumn{2}{|c|}{ Patients with itchiness }} & 118 & 77.1 & 153 & 46 & 83.6 & 55 & 0.343 \\
\hline & & Range & $\begin{array}{l}\text { Mean }[\mathrm{SD}] \\
\text { or median }\end{array}$ & $\mathrm{N}$ & Range & or median & $\mathrm{N}$ & \\
\hline Age (yr) & & $30.3-64.9$ & 54.2 & 153 & $21.1-65.0$ & 59.1 & 56 & $<0.001$ \\
\hline Duration o & s (months) & $4-325$ & 73 & 153 & $6-335$ & 56 & 56 & 0.617 \\
\hline $\mathrm{Kt} / \mathrm{V}$ & & $0.80-2.29$ & 1.31 & 153 & $0.70-1.81$ & 1.28 & 56 & 0.900 \\
\hline SF-36 subs & re of physical functioning & $15-100$ & 85 & 153 & $10-95$ & 82.5 & 56 & 0.003 \\
\hline Task-orien & ng with stress & $16-79$ & $50.1[12.5]$ & 153 & $16-74$ & $48.8[13.2]$ & 56 & 0.481 \\
\hline Emotion-o & coping with stress & $16-76$ & 33 & 153 & $18-68$ & 37 & 56 & 0.020 \\
\hline HADS dep & score & $0-17$ & 5 & 153 & $0-\quad 13$ & 6 & 56 & 0.014 \\
\hline HADS anx & & $0-18$ & 4 & 153 & $0-\quad 12$ & 5 & 56 & 0.318 \\
\hline Internal he & us of control & $5-25$ & 17 & 153 & $0-\quad 25$ & 18 & 55 & 0.091 \\
\hline Self-effica & & $36-96$ & 79 & 152 & $42-96$ & 81 & 55 & 0.571 \\
\hline Social sup & & $21-89$ & 63 & 153 & $16-\quad 89$ & 65 & 55 & 0.657 \\
\hline
\end{tabular}

Employment was defined using the latest International Labour Organization definitions. SF-36: The Short Form-36 Health Survey. Task- and emotion-oriented coping with stress was evaluated using the Japanese version of the Coping Inventory for Stressful Situations. HADS: The Hospital Anxiety and Depression Scale. Internal health locus of control was evaluated using the Japanese version of the Health Locus of Control Scale. Self-efficacy was evaluated using the Self-Efficacy on Health-Related Behavior Scale. Social support was evaluated using the Social Support Scale. N may vary due to missing data.

comorbidities $)^{20-24)}$, we found physical functioning to be significantly associated with employment in men, and gastrointestinal disease as a comorbidity to be significantly associated with employment in women. Age was also significantly associated with employment in men. The association between EOC and employment was significant even after controlling for these factors.

The relationship between marital status and employment was significant and inversely correlated between the sexes. Men who were married were very likely to be employed, whereas women who were married were not. For men, spousal support for employment may have been a factor. In addition, it is possible that patients receiving HD exhibited traditional gender roles in which married men worked and married women kept house. For each sex, the association between EOC and employment was still significant after controlling for marital status.

Employed patients of either sex were less depressed, and employed women were less anxious. To our knowledge, no previous studies have examined the relationship between employment and depression and anxiety in patients receiving dialysis, although one study did report an association between SF-36 psychosocial summary scores and employment ${ }^{24)}$. The relationship between employment and depression found in the present study was consistent with the results of studies performed on the general population ${ }^{44,45)}$. As depression and/or anxiety in the general population seem to be associated with TOC and/or EOC ${ }^{46-48)}$, depression and anxiety could be confounders. However, the association between EOC and employment remained significant in multivariate analyses that included depression and anxiety.

Studies on the general population have indicated that self-efficacy is negatively associated with $\mathrm{EOC}^{2,7)}$, and that the internal health locus of control is negatively associated with stress, depression, and anxiety ${ }^{46,49}$. In a 
Table 3. Female patients' demographic, clinical and psychological characteristics and significances of their differences by employment

\begin{tabular}{|c|c|c|c|c|c|c|c|c|}
\hline & & \multicolumn{3}{|c|}{ Employed patients } & \multicolumn{3}{|c|}{$\begin{array}{l}\text { Unemployed or economically } \\
\text { inactive patients }\end{array}$} & \multirow[t]{2}{*}{$p$-value } \\
\hline & & $\mathrm{n}$ & $\%$ & Total n & $\mathrm{n}$ & $\%$ & Total n & \\
\hline \multirow{2}{*}{\multicolumn{2}{|c|}{$\begin{array}{l}\text { Married } \\
\text { Living with someone }\end{array}$}} & 17 & 54.8 & 31 & 61 & 79.2 & 77 & 0.017 \\
\hline & & 24 & 77.4 & 31 & 72 & 94.7 & 76 & 0.013 \\
\hline \multirow[t]{3}{*}{ Education } & Less than $12 \mathrm{yr}$ & 5 & 16.1 & 31 & 16 & 20.8 & 77 & 0.452 \\
\hline & $12 \mathrm{yr}$ & 16 & 51.6 & & 41 & 53.2 & & \\
\hline & More than $12 \mathrm{yr}$ & 10 & 32.3 & & 20 & 26.0 & & \\
\hline \multicolumn{2}{|c|}{ Diabetes mellitus as the cause of renal failure } & 4 & 12.9 & 31 & 13 & 16.9 & 77 & 0.773 \\
\hline \multicolumn{2}{|c|}{ Patients with cardiovascular disease } & 3 & 9.7 & 31 & 6 & 7.8 & 77 & 0.714 \\
\hline \multirow{2}{*}{\multicolumn{2}{|c|}{ Patients with gastrointestinal disease }} & 12 & 38.7 & 31 & 18 & 23.4 & 77 & 0.153 \\
\hline \multirow{2}{*}{\multicolumn{2}{|c|}{ Patients with itchiness }} & 25 & 80.6 & 31 & 54 & 70.1 & 77 & 0.340 \\
\hline & & Range & $\begin{array}{l}\text { Mean }[\mathrm{SD}] \\
\text { or median }\end{array}$ & $\mathrm{N}$ & Range & $\begin{array}{l}\text { Mean }[\mathrm{SD}] \\
\text { or median }\end{array}$ & $\mathrm{N}$ & \\
\hline \multicolumn{2}{|l|}{ Age (yr) } & $28.8-64.1$ & 51.4 & 31 & $32.2-65.0$ & 54.1 & 77 & 0.208 \\
\hline \multicolumn{2}{|c|}{ Duration of dialysis (months) } & $24-243$ & 142 & 31 & $3-331$ & 118 & 77 & 0.537 \\
\hline \multicolumn{2}{|l|}{$\mathrm{Kt} / \mathrm{V}$} & $1.09-1.77$ & 1.50 & 31 & $1.10-2.34$ & 1.45 & 77 & 0.734 \\
\hline \multicolumn{2}{|c|}{ SF-36 subscale score of physical functioning } & $5-100$ & 85 & 31 & $15-100$ & 75 & 77 & 0.104 \\
\hline \multicolumn{2}{|c|}{ Task-oriented coping with stress } & $21-72$ & $48.3[12.0]$ & 31 & $16-72$ & 47.0 [11.7] & 77 & 0.613 \\
\hline \multicolumn{2}{|c|}{ Emotion-oriented coping with stress } & $17-65$ & 29 & 31 & $16-61$ & 38 & 77 & 0.038 \\
\hline \multicolumn{2}{|c|}{ HADS depression score } & $0-13$ & 4 & 31 & $0-\quad 15$ & 6 & 77 & 0.020 \\
\hline \multicolumn{2}{|c|}{ HADS anxiety score } & $0-13$ & 4 & 31 & $0-19$ & 6 & 77 & 0.047 \\
\hline \multicolumn{2}{|c|}{ Internal health locus of control } & $0-25$ & 17 & 29 & $5-25$ & 18 & 77 & 0.869 \\
\hline \multicolumn{2}{|c|}{ Self-efficacy } & $27-96$ & 76 & 30 & $34-94$ & 77 & 76 & 0.843 \\
\hline \multicolumn{2}{|c|}{ Social support } & $24-80$ & 57 & 31 & $29-80$ & 60 & 76 & 0.392 \\
\hline
\end{tabular}

Footnotes are the same as for Table 2.

Table 4. Odds ratios of unemployed or economically inactive status in males in association with various factors from the multiple logistic regression analyses using a forward, stepwise method

\begin{tabular}{lcccc}
\hline & Wald & Odds ratio & $95 \%$ CI & $p$-value \\
\hline Emotion-oriented coping with stress (per 10 points) & 4.7 & 1.48 & $1.04-2.11$ & 0.030 \\
Married (vs. others) & 11.8 & 0.16 & $0.05-0.45$ & 0.001 \\
Age (per 10 yr) & 7.6 & 2.12 & $1.24-3.61$ & 0.006 \\
SF-36 subscale score of physical functioning (per 10 points) & 6.6 & 0.80 & $0.67-0.95$ & 0.010 \\
Internal health locus of control (per 10 points) & 3.3 & 2.26 & $0.93-5.46$ & 0.070 \\
Social support (per 10 points) & 3.2 & 1.29 & $0.97-1.71$ & 0.075 \\
Complication with cardiovascular disease (vs. none) & 2.9 & 2.91 & $0.85-9.98$ & 0.090 \\
\hline
\end{tabular}

For continuous variables, the odds ratio represents the change in the odds ratio of unemployed or economically inactive status associated with a 10-unit increase of the variable. 95\% CI: 95\% confidence interval of odds ratio. Emotion-oriented coping with stress was evaluated using the Japanese version of the Coping Inventory for Stressful Situations. SF-36: The Short Form-36 Health Survey. Internal health locus of control was evaluated using the Japanese version of the Health Locus of Control Scale. Social support was evaluated using the Social Support Scale. 
Table 5. Odds ratios of unemployed or economically inactive status in females in association with various factors from the multiple logistic regression analyses using a forward, stepwise method

\begin{tabular}{lcccc}
\hline & Wald & Odds ratio & 95\% CI & $p$-value \\
\hline Emotion-oriented coping with stress (per 10 points) & 4.1 & 1.88 & $1.02-3.46$ & 0.042 \\
Married (vs. others) & 7.8 & 4.75 & $1.59-14.19$ & 0.005 \\
HADS depression score (per 10 points) & 4.4 & 6.22 & $1.12-34.43$ & 0.036 \\
Self-efficacy (per 10 points) & 3.4 & 1.55 & $0.97-2.46$ & 0.066 \\
Complication with gastrointestinal disease (vs. none) & 6.4 & 0.23 & $0.08-0.72$ & 0.012 \\
Symptom of itchiness (vs. none) & 2.7 & 0.35 & $0.10-1.23$ & 0.103 \\
\hline
\end{tabular}

For continuous variables, the odds ratio represents the change in the odds ratio of unemployed or economically inactive status associated with a 10-unit increase of the variable. 95\% CI: 95\% confidence interval of odds ratio. Emotion-oriented coping with stress was evaluated using the Japanese version of the Coping Inventory for Stressful Situations. HADS: The Hospital Anxiety and Depression Scale. Self-efficacy was evaluated using the Self-Efficacy on Health-Related Behavior Scale.

healthy population, social support tends to be negatively associated with vocational strain ${ }^{50,51)}$. Thus, self-efficacy, the internal health locus of control, and social support could be confounders. However, the association between EOC and employment was significant even in multivariate analyses including these factors.

In the present study, the mean TOC scores were high, but not significant, in employed patients. In patients receiving maintenance HD, TOC may not be important in relation to employment.

This study had some limitations. As this was a crosssectional study, it was not possible to determine causal relationships. EOC may cause maladjustment to the work environment or patients may become emotional because they are not employed. Both are possible. The two could even form a vicious circle, producing a stronger association between EOC and not being employed. Vocational rehabilitation could be useful for EOC and a better system of providing work opportunities for disabled people would lead to lower unemployment among them. Either could break the possible vicious circle.

Another limitation is that as the study used convenience sampling, the results may not be applicable to all patients receiving HD in Japan. Owing to the complexity of the inclusion criteria, it was difficult to compare the study population and the total eligible HD population in Japan. Our results should be confirmed in future studies.

\section{Conclusions}

The results of the present study indicate that EOC is associated with employment in patients receiving maintenance HD, but that TOC is not. The number of patients undergoing dialysis is increasing ${ }^{18)}$, and dialysis patients would benefit from achieving economic independence, as would society as a whole. The present results may lead to new approaches benefitting persons with physical disabilities.
Acknowledgments: The authors wish to thank Yoshimi Suzukamo for use of the SF-36 Health Survey, Monika Spesova and the staff at Multi-Health Systems Inc. for permission to use the Japanese version of the Coping Inventory for Stressful Situations (CISS), Toshiaki Furukawa for use of CISS, Yuko Horige for use of the Japanese version of the Health Locus of Control Scale, Woe Sook Kim for use of the Self-Efficacy on HealthRelated Behavior Scale and the Social Support Scale, and Tadahiro Nishi, Hiromi Shimoyama, Toshio Inada, and Norimasa Matsuyama for allowing us access to their facilities.

\section{References}

1) Endler NS, Parker JDA. Coping Inventory for Stressful Situations (CISS): Manual. Toronto: Multi-Health Systems Inc., 1990.

2) Lazarus RS. Psychological stress in the workplace. In: Crandall R, Perrewe PL, eds. Occupational stress. Washington DC: Taylor \& Francis, 1995: 3-14.

3) SA Stumpf and AP Brief: Self-efficacy expectations and coping with career-related events. J Vocat Behav 31, 91-108 (1987)

4) DJ Terry, L Tonge and VJ Callan: Employee adjustment to stress: the role of coping resources, situational factors, and coping response. Anxiety Stress Coping 8, 1-24 (1995)

5) P Norman, S Collins, M Conner, R Martin and J Rance: Attributions, cognitions, and coping styles: teleworkers' reactions to work-related problems. J Appl Soc Psychol 25, 117-128 (1995)

6) GT Patterson: Examining the effects of coping and social support on work and life stress among police officers. J Clim Justice 31, 215-226 (2003)

7) K Chwalisz, EM Altmaier and DW Russell: Causal attributions, self-efficacy cognitions, and coping with stress. J Soc Clin Psychol 11, 377-400 (1992)

8) SF Sears Jr, GG Urizar Jr and GD Evans: Examining a stress-coping model of burnput and depression in extension agents. J Occup Health Psychol 5, 56-62 
(2000)

9) M Koleck, M Bruchon-Schweitzer, E Thiebaut, N Dumartin and Y Sifakis: Job stress, coping and burnout among French general practitioners. Eur Rev Appl Psychol 50, 309-314 (2000)

10) EA Knight: Perceived control and actual outcomes of hassle situations on the job. Psychol Rep 67, 891-898 (1990)

11) ZD Gellis: Coping with occupational stress in healthcare: a comparison of social workers and nurses. Adm Soc Work 26, 37-52 (2002)

12) CP O'Neill and A Zeiner: Working women: a study of relationships between stress, coping and health. J Psychosom Obstet Gynaecol 4, 105-116 (1985)

13) D Strutton and JR Lumpkin: The relationship between optimism and coping styles of salespeople. J Pers Selling Sales Manage 8, 71-82 (1993)

14) D Strutton and JR Lumpkin: Relationship between optimism and coping strategies in the work environment. Psychol Rep 71, 1179-1186 (1992)

15) D Strutton and JR Lumpkin: Problem- and emotionfocused coping dimensions and sales presentation effectiveness. J Acad Mark Sci 22, 28-37 (1994)

16) KW Boey: Coping and family relationships in stress resistance: a study of job satisfaction of nurses in Singapore. Int J Nurs Stud 35, 353-361 (1998)

17) Kousei Toukei Kyoukai (Health and Welfare Statistics Association): Kokumin Eisei no Doukou. Kousei no Shihyou (J Health Welf Stat) 51, 105-109 (2004) (in Japanese)

18) An Overview of Regular Dialysis Treatment in Japan (as of Dec. 31, 2003). Tokyo: Japanese Society for Dialysis Therapy, 2004: 3-20 (in Japanese).

19) Kousei Toukei Kyoukai (Health and Welfare Statistics Association): Kokumin Eisei no Doukou. Kousei no Shihyou (J Health Welf Stat) 51, 203-220 (2004) (in Japanese)

20) RA Gutman, WW Stead and RR Robinson: Physical activity and employment status of patients on maintenance dialysis. N Engl J Med 304, 309-313 (1981)

21) JL Holley and S Nespor: An analysis of factors affecting employment of chronic dialysis patients. Am J Kidney Dis 23, 681-685 (1994)

22) RB Curtin, ET Oberley, P Sacksteder and A Friedman: Differences between employed and nonemployed dialysis patients. Am J Kidney Dis 27, 533-540 (1996)

23) C Blake, MB Codd, A Cassidy and YM O'Meara: Physical function, employment and quality of life in end-stage renal disease. J Nephrol 13, 142-149 (2000)

24) JG Van Manen, JC Korevaar, FW Dekker, MC Reuselaars, EW Boeschoten and KT Krediet: NECOSAD study group: netherlands cooperative study on adequacy of dialysis. Changes in employment status in end-stage renal disease patients during their first year of dialysis. Perit Dial Int 21, 595-601 (2001)

25) T Furukawa, A Suzuki-Moor, Y Saito and T Hamanaka: Reliability and validity of the Japanese version of the coping inventory for stressful situations: a contribution to the cross-cultural studies of coping. Psychiatr Neurol
Jpn 95, 602-621 (1993) (in Japanese)

26) JE Ware and CD Sherbourne: The MOS 36-item shortform health survey (SF-36). I. Conceptual framework and item selection. Med Care 30, 473-480 (1992)

27) S Fukuhara, S Bito, J Green, A Hsiao and K Kurokawa: Translation, adaptation, and validation of the SF-36 Health Survey for use in Japan. J Clin Epidemiol 51, 1037-1044 (1998)

28) J Takaki, T Nishi, H Shimoyama, T Inada, N Matsuyama, H Kumano and T Kuboki: Interactions among a stressor, self-efficacy, coping with stress, depression, and anxiety in maintenance hemodialysis patients. Behav Med 29, 107-112 (2003)

29) Bandura A. Social learning theory. New York: Prentice Hall, 1977.

30) WS Kim, H Shimada and Y Sakano: The relationship between self-efficacy on health behavior and stress responses in chronic disease patients. Jpn J Psychosom Med 36, 499-505 (1996) (in Japanese)

31) KA Wallston, BS Wallston and R Devellis: Development of the multidimentional health locus of control (MHLC) scales. Health Educ Monogr 6, 160170 (1978)

32) Y Horige: A Japanese version of the health locus of control scales. Rinsho-Shinrigaku-Kenkyu 4,1-7 (1991) (in Japanese)

33) WS Kim, H Shimada and Y Sakano: Effects of social support and self-efficacy on psychological stress responses in chronic disease patients. Jpn J Psychosom Med 38, 317-323 (1998) (in Japanese)

34) AS Zigmond and RP Snaith: The hospital anxiety and depression scale. Acta Psychiatr Scand 67, 361-370 (1983)

35) AS Zigmond and RP Snaith (translated by T Kitamura): Hospital anxiety and depression scale (HAD shakudo). Seishinka-Shindangaku 4, 371-372 (1993) (in Japanese)

36) A Higashi, H Yashiro, K Kiyota, H Inokuchi, H Hatta, K Fujita, Y Watanabe and K Kawai: Validation of the hospital anxiety and depression scale in a gastrointestinal clinic. Nihon-Shoukakibyougakkai-Zasshi 93, 884-892 (1996) (in Japanese)

37) H Hatta, A Higashi, H Yashiro, K Ozawa, K Hayashi, H Inouchi, J Ikeda, K Fujita, Y Watanabe and K Kawai: A validation of the hospital anxiety and depression scale. Jpn J Psychosom Med 38, 309-315 (1998) (in Japanese)

38) JT Daugirdas: Second-generation logarithmic estimates of single-pool variable volume of $\mathrm{Kt} / \mathrm{V}$ : an analysis error. J Am Soc Nephrol 4, 1205-1213 (1993)

39) JT Ptacek, RE Smith and KL Dodge: Gender differences in coping with stress: when stressor and appraisals do not differ. Pers Soc Psychol Bull 20, 421430 (1994)

40) JT Ptacek, RE Smith and J Zanas: Gender, appraisal, and coping: a longitudinal analyses. J Pers 60, 747770 (1992)

41) SPK Jena: Job, life satisfaction and occupational stress of women. Soc Sci Int 15, 75-80 (1999)

42) TE Hurst and MM Hurst: Gender differences in 
medication of severe occupational stress among correctional officers. Am J Clim Justice 22, 121-137 (1997)

43) K Korabik and JV Kampen: Gender, social support, and coping with work stressors among managers. J Soc Behav Pers 10, 135-148 (1995)

44) D Schwefel: Unemployment, health and health services in German-speaking countries. Soc Sci Med 22, 409430 (1986)

45) PE Bebbington: Psychosocial causes of depression. J Gend Specif Med 2, 52-60 (1999)

46) VJ Callan, DJ Terry and R Schweitzer: Coping resources, coping strategies and adjustment to organizational change: direct or buffering effects? Work Stress 8, 372-383 (1994)

47) PP Heppner, SW Cook, AL Strozier and MJ Heppner: An investigation of coping styles anf gender differences with farmers in career transition. J Couns Psychol 38, 167-174 (1991)

48) K Kitaoka-Higashiguchi, H Nakagawa, Y Morikawa, M Ishizaki, K Miura, Y Naruse, T Kido, and M Sukigara: Social support and individual styles of coping in the Japanese workplace: an occupational stress model by structural equation analysis. Stress Health 19, 37-43 (2003)

49) DM Gates: Stress and coping. A model for the workplace. AAOHN J 49, 390-398 (2001)

50) PJ Decker and FH Borgen: Dimensions of work appraisal: stress, strain, coping, job satisfaction, and negative affectivity. J Couns Psychol 40, 470-478 (1993)

51) P Landsbergis and T Theorell: Measurement of psychosocial workplace exposure variables. Occup Med 15, 163-188 (2000) 